\title{
Disputed Land Claims: A Response to Weatherson and to Bou-Habib and Olsaretti
}

\section{Hillel Steiner and Jonathan Wolff}

In a paper published in this journal we proposed a method for resolving disputed land claims between two parties (Steiner and Wolff: 2003). In essence the proposal is to hold an auction between the disputants in which the land is given to the higher bidder, but the receipts of the auction to the under-bidder. We claimed that under such circumstances both parties can walk away happy: the higher bidder happy to pay the price bid for the land; the under-bidder happier to have the receipts of the auction when the alternative is to pay for the land at a higher price.

In the following issue Brian Weatherson registered not one but nine objections to this proposal, concluding that it 'favours rich, secretive, belligerent states that are disposed to make spurious land claims over poor, democratic, pacifist states that only make genuine land claims' (Weatherson 2003: 327). Subsequently, Paul Bou-Habib and Serena Olsaretti argued that our proposal 'unduly disadvantages bidders with reasonably broad conceptions of the good life relative to bidders with unduly narrow conceptions of the good life'. (Bou-Habib and Olsaretti: 2004, 285) If both objections are correct, we look forward to an auction between a rich, secretive, belligerent, dishonest state and a poor but open one with an unduly narrow conception of the good life. However, whether the objections are correct is a matter of some subtlety. It is all very well to allege that the solution has certain properties claimed to be undesirable; but even if the solution does have such properties, and even if these properties are undesirable, it may still not be immediately clear what force the objections have. We 
are grateful to our critics for bringing us to focus in more depth both on the proposal itself and the surrounding methodological issues.

To provide some more context it is worth highlighting a question that has been pressed on us, although not in either of the published responses: in what sense do we intend our proposal to be a solution? Is it a solution which represents a morally desirable outcome or is it something closer to a pragmatic modus vivendi? We don't find this an easy question to answer. At present, we think the right thing to say is that it is intended to be a 'moral solution in the circumstances', but without pretending that it will repair pre-existing ills or injustices which are not themselves part of the dispute in question. So it is a proposal of modest scope. We do not claim that following this procedure will transform an unjust world order into a perfectly just one. Rather, like a legal decision in the civil courts, it concerns only what is immediately before it.

To see this another way, it is worth asking why we didn't make an even simpler proposal: settle the dispute by flipping a fair coin. Our argument is that both sides would, ex ante, prefer to settle the dispute by our modified auction procedure rather than by flipping a coin. If it is also the case that no other procedure would be preferred by both sides to ours, then there is a strong case that it is the morally best solution in the circumstances. However we do not argue there is no procedure that both sides would prefer; indeed we would not know how. All we can say is that we haven't been able to think of one or to have seen one in the writings of others. Nevertheless, if there were a case where both parties would prefer to flip a coin, then we would see no merit in our proposal. Indeed if either party would prefer the coin flip then again we would abandon our proposal in such a case. However, although we will ourselves provide cases where one party may well prefer a coin flip, neither of the critical responses, in our view, presents such cases. 
Before looking at the objections in detail it is worth responding to yet another objection that has been put to us many times and is mentioned and responded to on our behalf by Bou-Habib and Olsaretti. The objection is that the auction will favour the party with deeper pockets. Now, what does 'favour' mean here? Bou-Habib and Olsaretti seem to assume that to be favoured is to be 'more likely to walk away with the land'. Accordingly, to avoid this result they assume that we would recommend that some steps should be taken to equalise bargaining power. However we do not see the problem in the same terms and thus would not adopt the offered solution. On our understanding, whether or not the auction favours one side is not the same as the question of who would end up with the land. It is true that it is likely that the wealthier party will often, although not always, gain the land, for it is a general truth that money buys you things that those without money cannot afford. But what is important to us is that the under-bidder also comes away with something with which they are happy. Earlier we put this in the somewhat vague formulation of 'something which, in the circumstances, it prefers to the land'. 'The circumstances', of course, refers to the fact that the land has a price, which, given the alternative of receiving money, the under-bidder does not want to pay.

Could it be that both parties will walk away happy in this sense, yet the auction is still unfair, in that it favours one party over the other? The obvious way of developing this objection is to say that there are systematic reasons why one party might reap more of the utility surplus than the other, which appears to be Weatherson's understanding of what it is to favour one party over the other. Yet this appears highly problematic, as it assumes what we might call full cardinal international comparisons of utility, which, as far as we know are yet to be understood. 
However we do not want to hide behind a technicality, and we must concede that intuitively it is not difficult to understand what is intended here. Is it true that more of the utility surplus, so conceived, will go to the wealthier party? If so, we would consider this a serious difficulty with our proposal. We will return to this below.

Yet there is a further worry. A poor nation may value the land very highly, yet not have the money to pay for it. Therefore it may be unable to bid up to its valuation in the auction and, like a pauper playing poker with millionaires, will have to withdraw before it would like to. Accordingly it may well prefer a coin toss. This is a serious objection, but it has a simple answer: credit. After all, how many of us are ever in the fortunate position to buy land (or indeed, among academics, anything) for cash? We borrow, and pay back in the long term. The test of how much a party values the land is not what figure, plucked from the air, they put on it, but what they are prepared to sacrifice, including what debt they are prepared to take on, and future sacrifices to pay that debt, to gain it. Now of course this doesn't show that the land will go to the poorer party; for the richer party can borrow too, and borrow more, and on better terms, most likely. However the point is that the higher the price the poorer party puts on the land and the more it is prepared to borrow, not only the more likely it is to gain the land, but the better off it will become if it is the under-bidder. For it will have forced up the price that the richer party will have to pay. So once sufficient money is available by means of credit, even a poor nation will have reason to prefer the auction to the coin flip.

However this does reveal an important assumption behind the auction, which is that each party has access to potentially unlimited sources of credit. Without this the poorer party may not be able to bankroll its bidding, and so would prefer a coin 
flip.. But where there is such access both would (we continue to claim) prefer the auction procedure.

We are now in a position to respond to Bou-Habib and Olsaretti's objection. They imagine that one party has an 'unduly narrow' conception of the good life, caring only about the land, and being prepared to divert all its resources to the auction, whereas the other party cares about such things as education, the environment, and public transport, wanting to reserve money for these purposes. According to this line of argument it is plausible that the former party will be prepared to bid higher for the land, and so, it is claimed, the auction unfairly favours this party. Now the reply to this may already be obvious. We do not accept this account of what it is to favour one party. The first test, rather, is whether this shows that either party would prefer the coin flip. We contend that it does not. Both parties will expect to be able to walk away happy. One will have the land, and the other a lot more money to spend on the things it values, such as education, the environment and public transport. The second test is whether any utility surplus will be systematically mal-distributed in favour of one party. We see no special reason why the width or narrowness of a party's conception of the good should have any bearing on this at all.

Now there may still be worries about Bou-Habib and Olsaretti's example. As they point out, even if the people are solid in their narrow conception of the good, there may be a feeling that they are making a big mistake in sacrificing so much simply for extra territory. ${ }^{1}$ This is certainly an important question, but it is not an

\footnotetext{
${ }^{1}$ This argument seems to be that the auction is unfair to the party with too narrow a conception of the good, which, of course, is distinct from their main objection which is that the auction is unfair to the party with a broad conception of the good.
} 
issue for us in this context. We should make clear once again that our proposal is very limited in scope - to find a way of resolving disputed land claims which is acceptable to both parties in the circumstances - not to heal all the ills of the world. ${ }^{2}$

So far we have assumed that both parties will prefer the auction procedure to a coin flip (provided they have access to credit). However Weatherson seems to contest even this, and, as his first of nine objections produces an example in which the auction is alleged to result in the poorer party walking away with an amount of money they do not, in the circumstances, prefer to the land. This, if correct, would create serious difficulties for our proposal, at least in respect to that example.

In Weatherson's example, Party A which values the land at 8 is bidding against Party B, which values the land at 12 . B has just bid 4 . A now has to decide whether to accept 4 or bid 4.5 (Weatherson assumes a minimum bidding increment of 0.5). Now, as Weatherson points out, putting in a bid of 4.5 values the land at 8.5 , for it involves forgoing the 4 units A would otherwise receive from B, as well as the 4.5 units that A would have to pay to $\mathrm{B}$. In this example $\mathrm{A}$ is assumed not to be bidding tactically and so will refrain from bidding at this point, receiving B's 4 and letting B have the land at that price. So Weatherson concludes that this is a case where 'the poorer party ends up with something it wants much less than the land'. Hence,

\footnotetext{
${ }^{2} \mathrm{~A}$ further problem is that perhaps it is only the rulers who care only about land; the people want other things too. In that case the problem is that the bidders do not reflect the values of their people. We concede that we have treated the parties to the auction as 'black boxes'; as if they were single, consistent, agents. If there is internal division then there is a serious problem, from which we have abstracted, but this is a difficulty for any theoretical approach to any problem in which states are treated as agents with preferences and values.
} 
contrary to our argument, 'There is no guarantee that the losing party will end up with something they prefer to the land' (2003: 322).

At first sight it looks as if Weatherson has pointed out a serious flaw. A values the land at 8 , but comes away with only 4 . However, Weatherson omits to include our qualifier which he carefully quoted earlier: that what counts is what they prefer 'in the circumstances' where the circumstances include having to pay for the land at its current auction price and forgoing the revenue that would have been generated by the rival's last bid. When that qualifier is included, Weatherson's criticism can be seen to be mistaken: getting 4 is better for A than getting the land at the price of 4.5.

Nevertheless getting only 4 units seems a bad result for A, relative to B's result of getting the land for 4 when B would have been prepared to pay up to 6 for the land. Would this be a reason, though, to reject the auction procedure? Consider our coin flip test. Would A prefer 4 to a $50 \%$ chance of something worth 8 ? Given standard assumptions about diminishing marginal utilities of money, the certainty of $£ n$ is always to be preferred to a $50 \%$ chance of $£ 2 n$. However, Weatherson appears to assume that utilities are linear with money for the sums involved. ${ }^{3}$ But even if we accept Weatherson's frankly counter-intuitive restriction, still A would be indifferent between receiving 4 and a 50\% chance of receiving something worth 8 . And given that, ex ante, A can have reason to believe that the worst outcome of the auction is to walk away with 4 but that many better outcomes are also possible, there is every reason to prefer the auction to the coin flip. Consequently it seems clear that in even

\footnotetext{
${ }^{3}$ Note that Weatherson concedes that some of his arguments are 'slightly vitiated' if we take declining marginal utility of money into account (2003: 322). This, in our view, is something of an under-statement.
} 
in this case, with all Weatherson's assumptions, A would have reason to prefer the auction to the coin flip.

Still, this doesn't answer the point that getting 4 looks like a bad result, given that $\mathrm{B}$, which put a value of 12 on the land, has had to pay only 4 for it, and thus has a gain of 8. Is this fair? Thus Weatherson's third objection may strike with force: 'If there's no tactical bidding the utility surplus is given entirely to the richer party'. (2003: 323) Although technically whether under such circumstances the entire surplus goes to the party which puts a higher valuation on the land depends on the order of bidding, and the size of minimum increments, we will let this pass, and accept this as a broadly correct observation. But is it reasonable to assume that there will be no tactical bidding? If $\mathrm{A}$ has an inkling that $\mathrm{B}$ gives a higher value to the land, then there is obvious scope for A's bidding the price up. This is why we said that, at a certain point, the problem reduces to a form of bargaining problem (although with some important differences), with the parties bargaining over the division of the surplus.

Suppose that the auction does reduce to a bargaining problem. The question of whether it is reasonable to assume that the parties are going to bid tactically then becomes the question of whether it is reasonable to expect them to be prepared to haggle over the price even when it has reached a level which is mutually profitable. How much skill and courage does one need for this? And does it correlate with wealth? To get some portion of the utility surplus one needs only the haggling skills of a tourist on a second visit to a street market. Note that in Weatherson's example A is curiously inept; not even having the wit to get a bid of 4 in first. ${ }^{4}$ But assuming

\footnotetext{
${ }^{4}$ Of course, contingencies of the particular way in which the auction is conducted may in some cases make this impossible.
} 
minimal competence, where the rest of the surplus ends up will depend on a number of factors, of which wealth is only one. A party which is more determined to get the land - such as Bou-Habib and Olsaretti's mono-culture - can be poorer yet in a stronger bargaining position.

However, the apparent fly in the ointment is that the auction procedure is not the same as a bargaining problem, for in the auction, as the price rises, all the risk falls on the party which puts a lower valuation on the land, and has to bid more than it would want to pay in order to raise the price (which in turn is necessary in order to have access to the utility surplus). The other party need not find itself in the exposed position of having to offer more than it wishes to pay. This appears to put the lowvaluation party at a relative disadvantage (even when both parties would prefer the auction to the coin flip). This is the force of Weatherson's fourth objection that 'Among the realistic outcomes the best case scenario for the poorer party is that it ends up with as large a utility surplus as the richer party.' (2002: 323) And, as Weatherson points out, best cases rarely happen, from which it would follow that normally the poorer party (strictly, the under-bidder who may actually be richer) comes away with less than half the utility surplus. Now this objection does appear to reveal something important; that there is an asymmetry of power, with the advantage going to the party prepared to pay the higher price.

Yet the situation is far more complex than Weatherson appears to appreciate. There is another asymmetry of power which this time favours the party with the lower valuation of the land. For suppose the party with the higher valuation has just bid at a point which equally divides the utility surplus. The other party may simply accept this, but it also has room for an audacious, greedy, move: to put in a bid to push the price up even higher. This carries substantial risk, of course, in that the higher- 
valuation party may call its bluff and refuse to bid any higher. But to do this would be to spite itself and to accept a course of action which yields less utility than simply putting in a higher bid. And if this talk of greed and spite sounds familiar, that is because we discussed this situation in the initial paper. The significance of this is that in the auction there are two asymmetries of power: the lower-valuation party has to take risks which the higher-valuation party never does; but equally the lowervaluation party has the opportunity to squeeze out more of the utility surplus by tactical bidding. The higher-bidder never faces either the risk or the opportunity. How the factors would work out in practice must depend on a host of considerations we cannot explore here, but it may, surprisingly, turn out that the bulk of the utility surplus goes to the under-bidder, provided it has a good estimate of the higherbidder's preferences and character. In consequence, however, Weatherson's objection that the best that the under-bidder can hope for is to achieve half the utility surplus is quite mistaken.

We have responded to three of Weatherson's objections. There are another six, which in effect point out either assumptions of the applicability of the model (such as that it assumes that the parties have equal moral claims on the land) or ancillary consequences of the bargaining methodology (such as that it favours the secretive over the open). In our view these are rather less important, and could equally have been called 'observations' as much as 'objections'.

In sum, our first ambition was to provide a way of resolving the dispute that both parties would prefer to a coin flip. We have pointed out ourselves that for groups with no access to credit the auction may not be attractive. But we not seen reason to give up the claim that in other cases both parties would prefer it, even under the highly restrictive assumptions of linear marginal utilities and no tactical bidding. 
Dropping those assumptions makes the auction procedure even more clearly superior to the coin flip, and we not think we have been given reasons to believe that it contains any systematic bias.

\author{
Hillel Steiner \\ Manchester Centre for Political Theory \\ University of Manchester \\ Manchester M13 9PL, UK \\ hillel.steiner@manchester.ac.uk \\ Jonathan Wolff \\ University College London \\ London WC1E 6BT \\ j.wolff@ucl.ac.uk
}

\title{
References
}

Bou-Habib, P, and S. Olsaretti. Land disputes and auctions. 2004. Analysis 64: 28487.

Steiner, H. and J. Wolff. 2003. A general framework for resolving disputed land claims. Analysis 63: 188-89.

Weatherson, B. 2003. Nine objections to Steiner and Wolff on land disputes. Analysis 63: 321-27. 